\title{
A TRADIÇÃO ALIMENTAR NO CONTEXTO DAS AGROINDÚSTRIAS FAMILIARES DE ALIMENTOS: O CASO DA MICRORREGIÃO NORTE DO COREDE DO VALE DO RIO PARDO - RS/BRASIL
}

\author{
Ana Claudia Guske 1 \\ Erica Karnopp ${ }^{2}$ \\ Virginia Elisabeta Etges ${ }^{3}$
}

Resumo: A partir da constatação de que existe um número relevante de agroindústrias familiares na Microrregião Norte do Conselho Regional de Desenvolvimento - Corede do Vale do Rio Pardo, contexto marcado pela produção de tabaco e soja, a presente pesquisa teve como objetivo analisar se a tradição alimentar, presente entre agricultores familiares, proprietários de agroindústrias familiares, se expressa enquanto ressignificação do saber-fazer das famílias frente à homogeneização dos hábitos alimentares promovidos pela globalização. Foram pesquisadas agroindústrias familiares formalizadas no período de 2000 a 2015, num total de 11 estabelecimentos. Concluiu-se que 75\% das agroindústrias familiares pesquisadas expressam tradição na sua produção, pois os alimentos agroindustrializados fazem parte da história da família. Esses alimentos não se contrapõem somente à homogeneização dos hábitos alimentares, mas rebatem a própria globalização.

Palavras-chave: Tradição. Agroindústrias Familiares. Alimentos.

\section{THE FOOD TRADITION IN THE CONTEXT OF THE FAMILIAR FOOD AGROINDUSTRIES: THE CASE OF THE NORTHERN MICROREGION COREDE DO RIO PARDO VALLEY - RS / BRAZIL}

Abstract: Based on the finding that there is a significant number of family agroindustries in the Northern Microp Region of the Corede do Rio Pardo Valley, a context marked by tobacco and soybean production, the present study aimed to analyze if the food tradition, present among family farmers, owners of family agroindustries, is expressed as a re-signification of the know-how of the families in front of the homogenization of the alimentary habits promoted by the globalization. The family agroindustries formalized between 2000 and 2015 were surveyed, comprising 11 establishments. It was concluded that $75 \%$ of the family agroindustries researched express tradition in their production, since agroindustrialized foods are part of family history. These foods are not only counteracted by the homogenization of eating habits, but also by globalization itself.

Keywords: Tradition. Family Agroindustries. Foods.

\footnotetext{
1 Universidade de Santa Cruz do Sul, Departamento de História e Geografia, Santa Cruz do Sul, Brasil, anaclaugsk@gmail.com, https://orcid.org/0000-0003-0869-0555

2 Universidade de Santa Cruz do Sul, Departamento de História e Geografia, Santa Cruz do Sul, Brasil, erica@unisc.br, https://orcid.org/0000-0001-5976-2331

3 Universidade de Santa Cruz do Sul, Departamento de História e Geografia, Santa Cruz do Sul, Brasil, etges@unisc.br, https://orcid.org/0000-0002-6976-8363
} 


\section{TRADICIÓN ALIMENTARIA EN EL CONTEXTO DE LAS AGROINDUSTRIAS ALIMENTARIAS FAMILIARES: EL CASO DE LA MICRORREGIÓN NORTE DEL COREDE VALLE DO RIO PARDO - RS/BRASIL}

Resumen: Basado en el hecho de que hay un número relevante de agronegocios familiares en la Microrregión del Norte del Consejo de Desarrollo Regional - Corede Vale do Rio Pardo, un contexto marcado por la producción de tabaco y soja, esta investigación tuvo como objetivo analizar si la tradición alimentaria, presente entre los agricultores familiares, propietarios de agroindustrias familiares, se expresa como una resignificación de los conocimientos de las familias que se enfrentan a la homogeneización de los hábitos alimentarios promovida por la globalización. Se investigaron las agroindustrias familiares formalizadas entre 2000 y 2015, en un total de 11 establecimientos. Se concluyó que el 75\% de las agroindustrias familiares encuestadas expresan tradición en su producción, ya que los alimentos agroindustrializados son parte de la historia familiar. Estos alimentos no solo se oponen a la homogeneización de los hábitos alimenticios, sino que también contrarrestan la globalización.

Palabras clave: Tradición. Agroindustrias Familiares. Comida.

\section{Introdução}

A globalização dos mercados e a consequente integração da economia modificam estruturas sociais em diferentes pontos do planeta. A vulnerabilidade social é a consequência mais imediata desse processo.

Em decorrência dos processos de reestruturação capitalista e do aumento da vulnerabilidade social e econômica no meio rural, apresenta-se crescente a tendência de diversificação produtiva na agricultura familiar. Nesse sentido, várias estratégias de desenvolvimento, determinadas por dinâmicas endógenas, têm sido identificadas, merecendo destaque as agroindústrias familiares.

A presente pesquisa investigou de que modo a tradição alimentar, enquanto prática relacionada ao saber-fazer, transmitida através de gerações, manifesta-se nas agroindústrias familiares, produtoras de alimentos, localizadas na Microrregião Norte do Corede do Vale do Rio Pardo, composto pelos municípios de Arroio do Tigre, Estrela Velha, Ibarama, Lagoa Bonita do Sul, Passa Sete, Segredo, Sobradinho e Tunas.

As agroindústrias familiares formalizadas são compreendidas como aquelas geridas pelo grupo familiar que cumprem as obrigações legais exigidas pelos órgãos competentes. Quando a agroindústria familiar possui laudos de licença sanitária, ambiental e da potabilidade da água, ela se torna legalizada, estando apta a receber o Selo Sabor Gaúcho. De acordo com os propósitos desta investigação, as agroindústrias familiares que atendem aos requisitos formais, comercializando os 
produtos alimentares conforme as determinações legais, são tratadas como agroindústrias familiares formalizadas.

Atualmente o Corede do Vale do Rio Pardo é um dos 28 Coredes do Estado do Rio Grande do Sul e conta com 23 municípios (FEE, 2015), fazendo parte de uma estratégia que visa o desenvolvimento das regiões. Caracteriza-se como uma "entidade de direito privado, organizada sob a forma de associação civil, sem fins lucrativos e com prazo de duração indeterminado" (SILVEIRA; CAMPOS, 2012, p. 210).

A localização do Corede do Vale do Rio Pardo estende-se desde a Encosta do Planalto Meridional, parte da Depressão Central e da Campanha, abrangendo a área central do Estado do Rio Grade do Sul, conforme mostra a Figura 1.

Figura 1: Microrregião Norte do Corede do Vale do Rio Pardo/RS

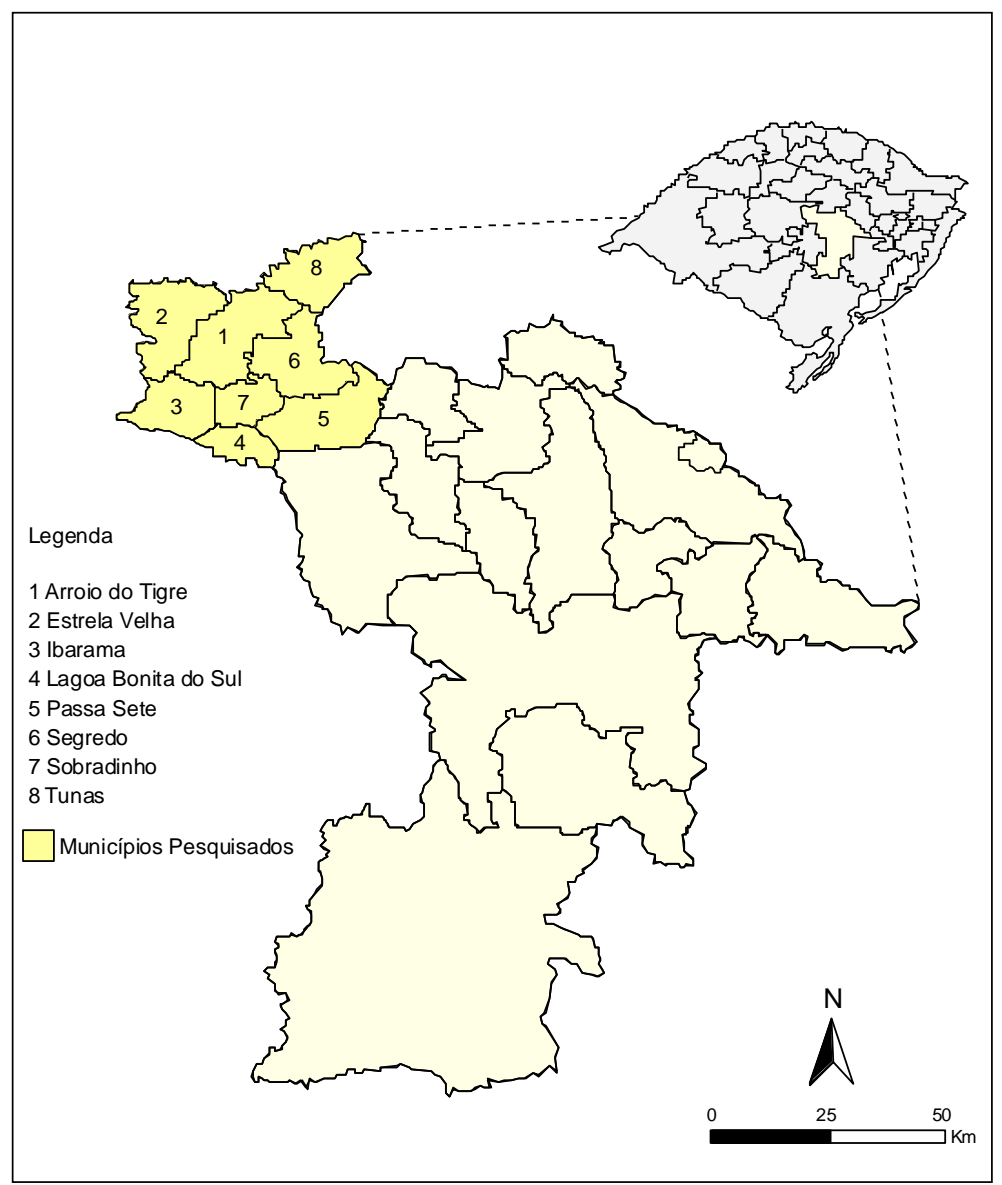

Fonte: FEE, 2009. Adaptado pelas autoras, 2016.

O Vale do Rio Pardo é caracterizado pela produção de tabaco e, segundo Karnopp et al. (2013), apresenta grande diversidade interna decorrente das 
características socioculturais, políticas e econômicas também diversas, presentes no processo de formação do território.

A Microrregião Norte do Corede do Vale do Rio Pardo, objeto desta pesquisa, caracteriza-se como "uma área de predomínio da pequena propriedade, com uma população constituída por descendentes de luso-brasileiros e de imigrantes alemães e italianos, com sérios problemas no tocante a alternativas econômicas que agreguem valor à produção do minifúndio" (KLARMANN, 1999, p. 147).

Nessa Microrregião existem aproximadamente 50 agroindústrias familiares de alimentos $^{4}$, sendo que $25 \%$ delas estão formalizadas ${ }^{5}$. A presença de um número relevante de agroindústrias de cunho familiar que produzem alimentos se mostra significativo no contexto em que estão inseridas.

Para atender ao proposto, foram utilizadas como técnicas de pesquisa entrevistas em formato semiestruturado, pesquisa bibliográfica, pesquisa documental e observação in loco. No contexto desta pesquisa foram selecionadas as agroindústrias formalizadas no período de 2000 a 2015 da Microrregião Norte do Corede do Vale do Rio Pardo, totalizando 11 famílias entrevistadas.

\section{Tradição alimentar no contexto regional}

A tradição alimentar é uma característica que pode se manifestar em diferentes grupos sociais. Está relacionada a aspectos identitários e a partir do contexto em que está inserida pode exteriorizar um posicionamento frente a aspectos globais.

Etimologicamente, a palavra "tradição" origina-se do latim traditio, um derivado de tradere e significa transmitir crenças ou técnicas de uma geração para outra (ABBAGNANO, 2007).

De acordo com Silva e Silva (2009, p. 408), a tradição possui muitos significados: pode estar atrelada ao conservadorismo
e ao resgate de períodos passados considerados gloriosos; pode ser
inventada para legitimar novas práticas apresentadas como antigas. Muitas
vezes é pensada como imóvel, mas hoje cada vez mais estudiosos
percebem suas ligações com as mudanças. Está ligada ao folclore, à cultura
e à formação de identidades. O estudo da tradição possui diversas vertentes de análise.

\footnotetext{
${ }_{4}^{4}$ Informação fornecida pelo Arranjo Produtivo Local de Agroindústria e Alimentos da Agricultura Familiar do Vale do Rio Pardo em julho de 2015.

${ }^{5}$ Informação fornecida pelos escritórios da Emater dos municípios pesquisados em fevereiro e março de 2016.
} 
Hobsbawm diferencia tradição de costume. A tradição se faz presente nas sociedades ditas tradicionais, é invariável, sendo que "o passado real ou forjado a que elas se referem impõe práticas fixas (normalmente formalizadas), tais como a repetição" (HOBSBAWM, 2014, p. 8). O costume, por sua vez, não impede inovações, podendo mudar até determinado ponto, ao contrário da tradição, que é invariável. O mesmo autor destaca que o costume, com o passar do tempo, adquire resistência às inovações por parte das pessoas que o adotaram.

Thompson (1998), no mesmo sentido, afirma que

um costume tem início e se desenvolve até atingir sua plenitude da seguinte maneira. Quando um ato razoável, uma vez praticado, é considerado bom, benéfico ao povo e agradável à natureza e à índole das pessoas, elas 0 usam e praticam repetidas vezes, e assim, pela frequente iteração e multiplicação do ato, ele se torna costume. (THOMPSON, 1998, p. 86).

A palavra hábito provém do latim habitus e significa "uma disposição constante ou relativamente constante para ser ou agir de certo modo" (ABBAGNANO, 2007, p. 495). Pacheco (2008) evidencia que o conceito de hábito pode ser confundido com o conceito de costume.

O hábito e o costume são semelhantes por tratarem de uma ação que se fixa com o exercício, de modo mecânico. Porém, "mais que uma sedimentação, o hábito é também disposição para ação" (PACHECO, 2008, p. 219). Assim, o hábito se refere a "uma atitude significativa, contextualizada e fruto de uma disposição adquirida" (PACHECO, 2008, p. 220), mas não carregada de simbologia, como a tradição.

Hobsbawm (2014, p. 8) utiliza o termo "tradição inventada" que, segundo o autor, pode ser entendida como

um conjunto de práticas, normalmente reguladas por regras tácitas ou abertamente aceitas; tais práticas de natureza ritual ou simbólica, visam inculcar certos valores e normas de comportamento através da repetição, o que implica, automaticamente, uma continuidade em relação ao passado.

Hobsbawm (2014) esclarece que as tradições são reações a situações novas, isto é, são meios de resistir às transformações do mundo. Nesse sentido, as tradições não são somente práticas aleatórias que remetem ao passado, mas são ações que se referem ao passado e que carregam significados frente às situações em que estão postas.

Por tradição alimentar, entende-se a produção de alimentos identificados como produtos com história, pois se constituem e fazem parte de uma determinada 
cultura, sendo produzidos com matéria-prima de uma determinada região. Devido aos conhecimentos e ao saber-fazer presentes nesses alimentos, através de gerações, a sua produção resgata não só a história envolta neles, mas o caráter histórico da agricultura familiar.

Nesta pesquisa, o termo "tradição alimentar" se torna apropriado no atendimento aos objetivos propostos, pois incita a investigar as simbologias expressas nos alimentos produzidos nas agroindústrias familiares da região em estudo, tornando-se particularmente relevante no contexto do desenvolvimento regional, uma vez que parte significativa da população desses municípios vive e trabalha no meio rural.

Nesse contexto, a globalização não deixa de ser considerada uma ameaça à sobrevivência das tradições alimentares. A partir do advento do capitalismo, da internacionalização do capital e da própria globalização, estabeleceram-se lutas simbólicas entre os interesses hegemônicos na busca pelo capital e entre aqueles que procuram preservar seus traços culturais tradicionais.

Eventos como a produção de alimentos tradicionais podem ser encarados como manifestações simbólicas não só contra a homogeneização alimentar, mas contra o modo de produção capitalista.

Poulain (2013, p. 33) esclarece que "as tradições alimentares, na sua função emblemática, tornam-se um lugar de resistência cultural”, pois historicamente o consumo de produtos caros e distantes, como é o caso das especiarias, indica uma posição social, a da nobreza. A valorização da tradição popular ligada aos alimentos está intimamente vinculada à industrialização dos alimentos, estando relacionada ao risco de diluição das identidades.

Compreender o espaço social alimentar permite entender a complexidade do processo dos modelos alimentares, em uma perspectiva geral. Os modelos alimentares incluem questões como a escolha dos alimentos disponibilizados no ambiente natural, a conexão do homem com a natureza e razões culturais, entre outras (POULAIN, 2013).

Portanto, a tradição alimentar da unidade familiar refere-se à presença de práticas alimentares passadas de geração para geração através do núcleo familiar. São modos de fazer que carregam aspectos identitários peculiares a um determinado grupo. Além de aspectos culturais, a tradição alimentar manifesta a 
especificidade do ambiente natural, pois faz uso de ingredientes provenientes da natureza.

\section{As agroindústrias familiares produtoras de alimentos na Microrregião Norte do Corede do Vale do Rio Pardo}

Os agricultores familiares, na condição de proprietários de agroindústrias familiares de alimentos, representam relações não tipicamente capitalistas de produção no contexto do modo de produção capitalista. Essas relações se caracterizam como não tipicamente capitalistas porque não há separação entre os trabalhadores e os meios de produção (OLIVEIRA, 2007).

A expressão da tradição, nessa conjuntura, é de substancial importância, pois o agricultor familiar transforma o seu conhecimento em uma alternativa produtiva mais autônoma frente aos mecanismos de dominação global, reagindo ao modo de produção capitalista.

Prezotto (2002) defende que a denominação de agroindústria rural de pequeno porte desempenha um novo papel no contexto rural buscando um novo modelo de desenvolvimento sustentável com alternativas econômicas para a permanência da agricultura familiar.

O modelo de desenvolvimento rural, do qual faz parte a agroindustrialização convencional, praticando a produção em grande escala, visa principalmente ao crescimento econômico, sem se preocupar com aspectos sociais e ambientais (PREZOTTO, 2002).

O autor explica que, a partir de 1960, houve uma intensa modernização da agricultura brasileira com a introdução do uso de maquinários agrícolas, fertilizantes, agrotóxicos e da manipulação genética de plantas e animais, cujo objetivo era aumentar a produtividade e produzir alimentos. Uma nova dinâmica foi introduzida, sendo que os agricultores que não atenderam a esses padrões estabelecidos foram excluídos.

Nessa perspectiva, Abramovay (1999, p. 39) reforça:

A paisagem rural do Sul do Brasil transformou-se de maneira impressionante nos últimos trinta anos. Durante a década de 1970, a especialização cultural tomou conta da maior parte da área agrícola com base em práticas predatórias, estimuladas não só por uma visão técnica que associava progresso material ao uso em larga escala de meios químicos e mecânicos de produção, mas também por um crédito rural fartamente subsidiado. 
O modo de produção capitalista, nesse contexto, separa os trabalhadores dos meios de produção. O empresário agrícola, por sua vez, detém a posse da terra e os meios de produção, sendo que os trabalhadores são contratados para vender sua força de trabalho. "Neste processo, a força de trabalho torna-se propriedade econômica do capitalista, algo que pertence ao capital e não ao trabalhador." (OLIVEIRA, 1995, p. 61).

Nesse meio, o surgimento da agroindústria rural é explicado por diversos autores:

\begin{abstract}
A agroindústria rural pode ser situada dentro de um movimento que alguns autores, como Marsden et al. (1992), denominam de um processo de "reestruturação dos espaços rurais" ou, na expressão de Goodman e Watts (1994), de "reconfiguração do rural e do capitalismo no sistema agroalimentar". Já para Bonano (1999), este mesmo processo é concebido como uma "transição do fordismo para um período pós-fordista da economia, da sociedade e do sistema agroalimentar". (IPEA, 2013, p. 13).
\end{abstract}

Porém, conforme Trentin e Wesz Junior (2004), as agroindústrias familiares fazem parte de um conjunto de ações que visam o desenvolvimento rural sustentável baseado na agricultura familiar, que aborda as perspectivas social, ambiental, cultural e econômico.

A agroindústria familiar produtora de alimentos, por suas características artesanais de produção, dispõe de um produto diferenciado e portador de qualidade. Essa produção, como consequência, valoriza a cultura regional, proporcionando oportunidades de desenvolvimento. É uma forma de diversificação produtiva, na medida em que uma mesma matéria-prima possibilita a produção de vários artigos. Um exemplo é a cana-de-açúcar, que pode originar produtos como o melado, o açúcar mascavo e a rapadura. Mior $(2005$, p. 73$)$ destaca que "a diversificação produtiva presente na agricultura familiar deveria ser incentivada como estratégia importante de desenvolvimento regional".

Com o propósito de investigar as agroindústrias familiares na Microrregião Norte de Corede do Vale do Rio Pardo, identificou-se, nesta pesquisa, treze agroindústrias familiares de alimentos formalizadas, conforme mostra o Quadro 1. Foram realizadas 11 entrevistas com as famílias proprietárias, pois duas agroindústrias pertencem ao mesmo grupo familiar e uma agroindústria familiar, localizada no Município de Arroio do Tigre, não concedeu entrevista. 


\section{Quadro 1: Agroindústrias familiares de alimentos na Microrregião Norte do Corede do Vale do Rio Pardo}

\begin{tabular}{|c|c|c|c|c|c|}
\hline \multirow{2}{*}{ Município } & \multicolumn{2}{|c|}{ Agroindústria } & \multirow{2}{*}{$\begin{array}{l}\text { Produção de } \\
\text { Origem }\end{array}$} & \multirow{2}{*}{$\begin{array}{l}\text { Segmento de } \\
\text { Produção }\end{array}$} & \multirow{2}{*}{ Zona } \\
\hline & TOTAL & Formalizadas & & & \\
\hline \multirow{7}{*}{ Arroio do Tigre } & \multirow{7}{*}{12} & \multirow{7}{*}{7} & Animal & Carne e Derivados & \multirow{7}{*}{ Rural } \\
\hline & & & Animal & Carne e Derivados & \\
\hline & & & Animal & Carne e Derivados & \\
\hline & & & Animal & Carne e Derivados & \\
\hline & & & Animal & Mandioca & \\
\hline & & & Vegetal & Mel & \\
\hline & & & Anima/Vegetal & Biscoitos & \\
\hline Estrela Velha & 2 & 0 & - & - & - \\
\hline Ibarama & 2 & 1 & Animal/Vegetal & Biscoitos & Rural \\
\hline Lagoa Bonita do Sul & 9 & 0 & - & - & - \\
\hline Passa Sete & 1 & 0 & - & - & - \\
\hline \multirow{2}{*}{ Segredo } & \multirow{2}{*}{11} & \multirow{2}{*}{2} & Animal & Carne e Derivados & Rural \\
\hline & & & Animal & Peixes & Rural \\
\hline \multirow{3}{*}{ Sobradinho } & \multirow{3}{*}{11} & \multirow{3}{*}{3} & Anima//Vegetal & Panifícios & \multirow{3}{*}{ Rural } \\
\hline & & & Anima//Vegetal & Massas & \\
\hline & & & Animal/Vegetal & Biscoitos & \\
\hline \multirow[t]{3}{*}{ Tunas } & 3 & 0 & - & - & - \\
\hline & 51 & 13 & & & \\
\hline & $100 \%$ & $25 \%$ & & & \\
\hline
\end{tabular}

Fonte: APLVRP (2015); Escritórios da Emater (2016). Organizado pelas autoras, 2016.

Para que as agroindústrias familiares fossem identificadas e localizadas, foi efetuado contato com o gestor do Arranjo Produtivo Local de Agroindústria e Alimentos da Agricultura Familiar do Vale do Rio Pardo - APLVRP, e com os técnicos dos escritórios da Associação Rio-Grandense de Empreendimentos de Assistência Técnica e Extensão Rural - Emater.

Após identificação e localização das agroindústrias, foram realizadas as visitas às famílias proprietárias de agroindústrias familiares.

O encontro com as famílias aconteceu, na maior parte das vezes, em dois momentos: o primeiro objetivou estabelecer contato com o grupo familiar, quando foi realizada visita à propriedade rural e apresentada a proposta da pesquisa. $O$ segundo encontro foi destinado à entrevista, que seguiu formato semiestruturado.

De acordo com os dados do Quadro 1, até dezembro de 2015 os municípios da Microrregião que não possuíam agroindústrias familiares formalizadas eram Estrela Velha, Lagoa Bonita do Sul, Passa Sete e Tunas. Isso, no entanto, não significa que esses municípios não contem com agroindústrias familiares de alimentos informais. Os dados mostram que o número de agroindústrias familiares informais é aproximadamente três vezes maior do que o número de agroindústrias que atuam conforme as exigências legais.

De acordo com Brutti (2012), um fator que dificulta a expansão das agroindústrias formalizadas é a dificuldade enfrentada na implementação do Sistema 
de Inspeção Municipal - SIM. Para a autora, enquanto as prefeituras não implantarem o SIM, as agroindústrias continuarão na informalidade. Entretanto, é preciso destacar que o projeto de uma agroindústria familiar deve ser um desejo da família e não uma imposição legal. Mais do que a simples formalização de agroindústrias familiares, o poder público deve buscar um projeto de desenvolvimento rural que valorize a experiência acumulada pelos agricultores familiares.

Como procedimento de levantamento dos dados foram estabelecidas três categorias, que são: tradição alimentar da unidade familiar, formação das agroindústrias familiares e relação entre tradição alimentar e o surgimento das agroindústrias. Dentro de cada categoria foram estabelecidas variáveis, como mostra o Quadro 2. 


\section{Quadro 2: Categorias e variáveis das agroindústrias familiares}

\begin{tabular}{|c|c|c|}
\hline Categorias de Análise & & Variáveis \\
\hline \multirow{4}{*}{$\begin{array}{l}\text { Tradição Alimentar } \\
\text { da Unidade Familiar }\end{array}$} & A & Origem étnica \\
\hline & $\mathrm{B}$ & Comidas preparadas \\
\hline & $\mathrm{C}$ & Comidas que lembram a infância \\
\hline & $\mathrm{D}$ & Gosto e preparação de comidas que fizeram parte da infância \\
\hline \multirow{8}{*}{$\begin{array}{c}\text { Formação das } \\
\text { Agroindústrias Familiares }\end{array}$} & A & Surgimento das agroindústrias \\
\hline & $\mathrm{B}$ & Período da formalização \\
\hline & $\mathrm{C}$ & Produto agroindustrial \\
\hline & $\mathrm{D}$ & Mão de obra \\
\hline & $\mathrm{E}$ & Origem da matéria-prima \\
\hline & $\mathrm{F}$ & Renda e volume de produção \\
\hline & $\mathrm{G}$ & Fonte de renda na propriedade \\
\hline & $\mathrm{H}$ & Apoio e formação técnica \\
\hline \multirow{6}{*}{$\begin{array}{c}\text { Relação entre tradição } \\
\text { alimentar e o surgimento das } \\
\text { agroindústrias }\end{array}$} & A & Alimentos industrializados \\
\hline & $\mathrm{B}$ & Autoconsumo do produto agroindustrial \\
\hline & $\mathrm{C}$ & Tradição presente na produção \\
\hline & $\mathrm{D}$ & Escolha do produto \\
\hline & $\mathrm{E}$ & Desempenho das atividades \\
\hline & $\mathrm{F}$ & Significado perante o global \\
\hline
\end{tabular}

Fonte: Elaborado pelas autoras, 2016.

Buscou-se, na primeira categoria (tradição alimentar da unidade familiar), identificar a tradição alimentar presente entre os agricultores familiares da região em estudo. Para tanto, foi necessário saber quais as comidas preparadas e consumidas usualmente pela família, quais as comidas que fizeram parte da infância e de que maneira elas ainda se fazem presente cotidianamente. Nesse contexto, a origem étnica da família é de fundamental importância.

$\mathrm{Na}$ segunda categoria objetivou-se caracterizar o processo de formação das agroindústrias familiares. Para isso, os proprietários foram consultados sobre o contexto em que se deu o surgimento da agroindústria, o período histórico de sua criação, sobre a escolha do(s) produto(s), a aquisição de insumos, o número de trabalhadores ao longo do tempo, o apoio e a formação técnica e sobre a importância da agroindústria como fonte de renda na propriedade.

Na terceira e última categoria de análise (relação entre tradição alimentar e o surgimento das agroindústrias), buscou-se analisar a relação entre tradição alimentar das famílias e o surgimento das agroindústrias. As famílias foram 
questionadas sobre os alimentos industrializados e seu significado para o grupo familiar, o significado deste tipo de alimento para a família, sobre o autoconsumo do(s) produto(s) proveniente(s) da agroindústria, da manifestação da tradição no(s) produto(s), de que modo o(s) alimento(s) é/são agroindustrializado(s) e, finalmente, o que significa a agroindústria perante o contexto global.

\section{Quadro 3: Motivação que impulsionou a criação das agroindústrias familiares}

\begin{tabular}{|c|c|c|c|}
\hline Categoria & $\%$ & Agroindústria & Variável \\
\hline \multirow{9}{*}{$\begin{array}{l}\text { Interferência } \\
\text { da conjuntura } \\
\text { global }\end{array}$} & \multirow{9}{*}{$75 \%$} & 1 & Intoxicação por agrotóxico utilizado no cultivo de tabaco; \\
\hline & & 2 & Intoxicação por agrotóxico utilizado no cultivo de tabaco; \\
\hline & & 3 & Doença na coluna ocasionado pelo cultivo de tabaco; \\
\hline & & 4 & Endividamento ocasionado pelo cultivo de tabaco; \\
\hline & & 5 & Alternativa para a produção de tabaco; \\
\hline & & 6 & Crise na venda de suínos; \\
\hline & & 7 & Crise na venda de suínos; \\
\hline & & 8 & Menos trabalhoso e venda garantida; \\
\hline & & 9 & $\begin{array}{l}\text { Alternativa que tivesse demanda e gerasse renda } \\
\text { satisfatória; }\end{array}$ \\
\hline \multirow{2}{*}{$\begin{array}{l}\text { Formalização } \\
\text { de uma } \\
\text { prática }\end{array}$} & \multirow{2}{*}{$17 \%$} & 10 & Gosto pessoal; \\
\hline & & 11 & Produção era constante na propriedade; \\
\hline Demanda & $8 \%$ & 12 & Demanda de clientes já fidelizados; \\
\hline TOTAL & $100 \%$ & 12 & - \\
\hline
\end{tabular}

Fonte: Elaborado pela autora, 2016.

A partir desta pesquisa, é possível concluir que $75 \%$ dos motivos citados para a criação de agroindústrias familiares são resultados do processo de imposição da globalização, pois são consequências perversas advindas de ações globais, comandadas por atores hegemônicos.

De acordo com Etges (2001, p. 360), o Vale do Rio Pardo é um

território monopolizado pelas empresas transnacionais fumageiras, a Região do Vale do Rio Pardo destaca-se por ser fortemente homogeneizada, tendo em vista que o oligopsônio fumageiro controla e centraliza todo o processo relativo à produção de tabaco: desde as técnicas utilizadas no cultivo, à comercialização da matéria-prima, ao seu beneficiamento e à sua industrialização, que resulta na produção de cigarro.

Entre as consequências perversas que o cultivo de tabaco provoca está o endividamento, a intoxicação, a depressão, a ansiedade, que em muitos casos, tem levado ao suicídio (GIRARDI, 2016). Essas características foram confirmadas pelas 
famílias entrevistadas, pois as mesmas justificaram a redução ou o abandono do cultivo do tabaco em decorrência de intoxicação, doença na coluna, endividamento, trabalho excessivo e geração de renda insatisfatória.

Cabe ressaltar que romper com a produção de tabaco depende de iniciativas empreendedoras da família, "pois os produtores muitas vezes estão desacostumados a enfrentar um mercado instável, uma vez que a 'facilidade' da garantia de compra da produção pelas empresas do tabaco acaba por inibir a iniciativa destes produtores, na busca de novos mercados para seus produtos" (KARNOPP, 2014, p. 145).

Assim, a partir das entrevistas realizadas foi possível verificar que $75 \%$ das agroindústrias familiares de alimentos expressam tradição na sua produção. Essas famílias mostraram que os alimentos agroindustrializados fazem parte da história da família e o saber-fazer, enquanto conhecimento repassado através de gerações está presente na produção agroindustrial.

As famílias deixaram claro que, devido às exigências sanitárias, alguns ajustes no processo produtivo foram necessários para que o alimento tradicional fosse agroindustrializado. No entanto, as famílias optam sempre por adicionar o mínimo de aditivos sintéticos exigidos pela legislação, pois buscam preservar o máximo de sabor original do produto agroalimentar, particularmente nas agroindústrias de embutidos.

As demais, $25 \%$ das famílias entrevistadas não expressam tradição na produção agroindustrial e encaram a agroindústria como uma oportunidade para a subsistência familiar e uma alternativa para a produção de tabaco. Nesses casos, os produtos agroindustrializados foram escolhidos a partir de variáveis mercadológicas, como demanda e ausência de concorrência. Nessas agroindústrias, os produtos não são tradicionais, mas, em algumas delas, são típicos, porque faziam parte da alimentação dos seus antepassados.

De modo geral, os entrevistados demonstraram que o produto alimentar que sai da agroindústria familiar apresenta qualidade e é diferenciado, se comparado com produtos provenientes da indústria alimentícia.

Segundo as famílias entrevistadas, o percentual de lucro gira em torno de $30 \%$. Assim, é possível concluir que, de acordo com o faturamento líquido, as agroindústrias familiares também se dividem em três categorias: $42 \%$ obtém renda 
de até $R \$ 3.000,00,25 \%$ obtém renda entre $R \$ 3.000,00$ e $R \$ 10.000,00$ e 33\% obtém renda acima de $R \$ 10.000,00$.

De modo geral, é possível perceber que

a agroindústria familiar é, do ponto de vista da geração de renda, de empregos e manutenção do homem nos espaços rurais, uma estratégia de reprodução social importantíssima da agricultura familiar e deve ser um dos "pilares" em que deve se assentar qualquer programa ou projeto de desenvolvimento rural para este setor a nível local ou territorial. (GAZOLLA; PELEGRINI, 2009, p. 14).

As famílias objetivam a manutenção do grupo social e não a acumulação de riqueza. Dessa forma, não visa somente satisfazer necessidades imediatas, mas garantir condições de sobrevivência às gerações futuras. A agroindústria familiar, neste sentido é um meio capaz de oferecer condições para que a reprodução social do grupo familiar se concretize.

\section{Considerações finais}

Os alimentos agroindustrializados pelas famílias entrevistadas se contrapõem à homogeneização dos hábitos alimentares promovidos pela globalização. No entanto, a produção agroindustrial dessas famílias ultrapassa a questão da homogeneização dos hábitos alimentares e rebate a própria globalização, pois a agroindústria é uma alternativa à produção de tabaco, que se apropria do território trazendo doenças, endividamento e trabalho árduo.

O trabalho na agroindústria é muito significativo para as famílias, pois a atividade agroindustrial transcende a manutenção do grupo familiar e a contraposição à globalização e valoriza a família, a história, fortalece a ligação entre o agricultor familiar e o camponês tradicional, preza a autonomia e estabelece um vínculo com a sociedade, ao promover o reconhecimento da família pela qualidade dos produtos comercializados.

Assim, quando um produto originário da agroindústria familiar é comercializado, ele não é somente um alimento agroindustrializado, ele representa uma história e é fruto de uma realidade em que as famílias buscam a manutenção do grupo familiar de forma autônoma.

Cabe destacar que, a partir do contexto em que estão inseridas, as famílias são extremamente empreendedoras, apresentam produtos padronizados que, de modo geral, obedecem às regras sanitárias estabelecidas. No entanto, as famílias 
poderiam explorar o caráter tradicional dos alimentos agroindustrializados por meio dos rótulos, por exemplo.

Evidenciou-se, portanto, que as agroindústrias familiares de alimentos da Microrregião Norte do Corede do Vale do Rio Pardo não só ressignificam o saberfazer das famílias frente à homogeneização dos hábitos alimentares, mas que estão carregadas de historicidade, marcada pela contradição, conflito e resistência no contexto em que estão inseridas.

No mesmo sentido de estudos elaborados por Gazolla e Pelegrini (2009), esta pesquisa conclui que as agroindústrias familiares da região pesquisada são uma importante estratégia de reprodução social e de promoção do desenvolvimento rural. Os empreendimentos agroindustriais de cunho familiar são capazes de gerar renda satisfatória para a manutenção do grupo familiar. Além disso, o trabalho na agroindústria familiar é fruto de uma escolha e é realizado com prazer, proporcionando satisfação durante a execução das atividades laborais e com o resultado do trabalho do familiar.

As agroindústrias familiares pesquisadas (re)valorizam o espaço rural, pois proporcionam melhor qualidade de vida às famílias rurais envolvidas no processo por meio de formas justas de reprodução social (WESZ JUNIOR; TRENTIN; FILIPPI, 2008). Além disso, a tradição enquanto aspecto cultural é valorizada e difundida, viabilizando o reconhecimento do território.

\section{REFERÊNCIAS}

ABBAGNANO, Nicola. Dicionário de filosofia. São Paulo: Martins Fontes, 2007.

ABRAMOVAY, Ricardo. O tortuoso caminho da sustentabilidade: tendências recentes da agricultura na região Sul. Agenda 21 Agricultura Sustentável. São Paulo: 1999. Disponível em: < http://www.fea.usp.br/feaecon//media/fck/File/O_tortuoso_caminho.pdf>. Acesso em: 20 ago. 2015.

FUNDAÇÃO DE ECONOMIA E ESTATÍSTICA - FEE. Perfil Socioeconômico RS - Coredes. Vale do Rio Pardo. Disponível em: <http://www.fee.rs.gov.br/perfilsocioeconomico/coredes/>. Acesso em: 30 mai. 2016.

GAZOLLA, M.; PELEGRINI, G. A agroindústria familiar: uma estratégia de agregação de valor a produção e renda das famílias rurais. In: 47ํㅡㄹ Congresso da Sociedade Brasileira de Economia e Sociologia Rural, Anais. Porto Alegre: 2009. Disponível em: <http://www.sober.org.br/palestra/13/183.pdf>. Acesso em: 10 nov. 2016.

GIRARDI, Giovana. Por que o Rio Grande do Sul é a região com mais suicídios do país.

Revista Galileu, São Paulo, n. 64, 2016.

HOBSBAWM, Eric J. Introdução: A invenção das tradições. In: HOBSBAWM, E. J.;

RANGER, T. (Org.). A invenção das tradições. Tradução de Celina Cardim Cavalcante. 9. ed. São Paulo: Paz e Terra, 2014. 
IPEA. O perfil da agroindústria rural no Brasil: uma análise com base nos dados do censo agropecuário 2006. Instituto de Pesquisa Econômica Aplicada. Brasília, 2013. Disponível em: <http://www.ufrgs.br/pgdr/arquivos/resultpesq/4.pdf>. Acesso em: 5 ago. 2015.

KARNOPP, E. et al. Agroindústrias familiares e a dinâmica territorial: um estudo comparativo entre a região do Vale do Rio Pardo/RS e a região do oeste catarinense/SC Brasil. Projeto de pesquisa. Santa Cruz do Sul, 2013.

KARNOPP, Erica. Repensando o desenvolvimento rural no contexto territorial da agricultura familiar: estudos de caso. Redes, Santa Cruz do Sul, v. 19, ed. especial, p. 139-152, 2014. KLARMANN, Herbert. Região e identidade regional: um estudo da espacialidade e representatividade regional no Vale do Rio Pardo. 1999. 189 f. Dissertação (Mestrado) Curso de Desenvolvimento Regional, Universidade de Santa Cruz do Sul, Santa Cruz do Sul, 1999.

MIOR, Luiz Carlos. Agricultores familiares, agroindústrias e redes de desenvolvimento rural. Chapecó: Argos, 2005.

OLIVEIRA, Ariovaldo Umbelino de. Modo capitalista de produção e agricultura. 4. ed. São Paulo: Ática, 1995.

Modo capitalista de produção, agricultura e reforma agrária. 1. ed. São Paulo:

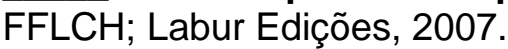

PACHECO, Sandra Simone Morais. O hábito alimentar enquanto um comportamento culturalmente produzido. In: FREITAS, M. do C. S.; FONTES, G. A. V.; OLIVEIRA, N. de (Orgs.). Escritas e narrativas sobre alimentação e cultura. p. 217-238. Salvador: EDUFBA, 2008.

POULAIN, Jean-Pierre. Sociologia da alimentação: os comedores e o espaço social alimentar. Tradução de Rossana Pacheco da Costa Proença, Carmen Sílvia Rial, Jaimir Conte. 2 ed. Florianópolis: Ed. da UFSC, 2013.

PREZOTTO, Leomar Luiz. Uma concepção de agroindústria rural de pequeno porte.

Revista de Ciências Humanas, EDUFSC. Universidade Federal de Santa Catarina. Centro de Filosofia e Ciências Humanas. Florianópolis. n. 31, p. 133-154, abr. 2002.

SILVA, K. V.; SILVA, M. H. Dicionário de conceitos históricos. São Paulo: Contexto, 2009.

SILVEIRA, R. L. L. da; CAMPOS, H. A. Processos participativos em experiências recentes de planejamento regional: o caso do vale do Rio Pardo (RS). Redes, Santa Cruz do Sul, v. 17, n. 1, p. 203-216, jan-abr 2012.

THOMPSON, Edward Palmer. Costumes em comum: estudos sobre a cultura popular tradicional. Tradução de Rosaura Eichemberg. São Paulo: Companhia das Letras, 1998. TRENTIN, I. C. L.; WESZ JUNIOR, V. J. Desenvolvimento e agroindústria familiar. In: Artigos Completos do XLII Congresso da Sociedade Brasileira de Economia e Sociologia Rural. Cuiabá: 2004.

WESZ JUNIOR, V. J.; TRENTIN, I. C. L.; FILIPPI, E. E. Os reflexos das agroindústrias familiares para o desenvolvimento das áreas rurais no Brasil. In: IV Congreso Internacional de la Red SIAL. Argentina: 2008. Disponível em:

<http://www.ufrgs.br/pgdr/arquivos/588.pdf>. Acesso em: 11 ago. 2015.

\section{NOTAS DE AUTOR}

\section{CONTRIBUIÇÃO DE AUTORIA}

Ana Claudia Guske- Concepção. Coleta de dados, Análise de dados, Elaboração do manuscrito, revisão e aprovação da versão final do trabalho

Erica Karnopp- Concepção e elaboração do manuscrito, Participação ativa da discussão dos resultados; Revisão e aprovação da versão final do trabalho.

Virginia Elisabeta Etges- Análise e discussão dos resultados; revisão e aprovação da versão final do trabalho. 


\section{FINANCIAMENTO}

Não se aplica.

\section{CONSENTIMENTO DE USO DE IMAGEM}

Não se aplica.

\section{APROVAÇÃO DE COMITÊ DE ÉTICA EM PESQUISA}

Não se aplica.

CONFLITO DE INTERESSES

Não há conflito de interesses.

\section{LICENÇA DE USO}

Este artigo está licenciado sob a Licença Creative Commons CC-BY. Com essa licença você pode compartilhar, adaptar, criar para qualquer fim, desde que atribua a autoria da obra.

\section{HISTÓRICO}

Recebido em: 03-04-2017

Aprovado em: 05-08-2019 